\title{
Correction to: Reversible cerebellar MRI hyperintensities and ataxia associated with hypomagnesemia: a case report with review of the literature
}

\author{
Andrea Rigamonti ${ }^{1} \cdot$ Vittorio Mantero $^{1} \cdot$ Giuseppe Lauria $^{2,3} \cdot$ Paola Basilico ${ }^{1} \cdot$ Andrea Salmaggi $^{1}$
}

Published online: 10 December 2019

(C) Fondazione Società Italiana di Neurologia 2019

Correction to: Neurological Sciences (2019)

https://doi.org/10.1007/s10072-019-04081-1

The above article was published online with inverted given and family names. The correct presentation has been corrected above.

Publisher's note Springer Nature remains neutral with regard to jurisdictional claims in published maps and institutional affiliations.

The online version of the original article can be found at https://doi.org/ 10.1007/s10072-019-04081-1

\footnotetext{
Andrea Rigamonti

rig74@libero.it

1 Neurological Department, ASST Lecco, Via Dell'Eremo 9/11, 23900 Lecco, Italy

2 Neuroalgology Units, Fondazione IRCCS Istituto Neurologico "Carlo Besta", Via Celoria 11, 20133 Milan, Italy

3 Department of Biomedical and Clinical Sciences "Luigi Sacco", University of Milan, Milan, Italy
} 